\title{
The Research and Application for the Method of the Intelligent Condition Evaluation about the Power Transmission Equipment
}

\author{
Junyu Dong ${ }^{1, a}$, Jie Wei ${ }^{1, b}$, Hong $\mathrm{Yu}^{1, \mathrm{c}}$, Shilin Jiang ${ }^{1, \mathrm{~d}}$, Bing Duan ${ }^{1, \mathrm{e}}$, Junxian \\ Dong ${ }^{1, \mathrm{f}}$, Rongdong $\mathrm{Li}^{1, \mathrm{~g}}$ \\ 1 Yunnan Power Grid Corporation, Kunming, 650000, China \\ aemail:1262842966@qq.com, bemail:HDliyaning@163.com, cemail: 894333697@qq.com
}

\begin{abstract}
Keywords: Running status, Evaluation, Power grid equipment
Abstract: Power transmission equipment condition is fatal in the power system. Incipient fault of transformer is detected as early as possible, which can make for reducing the loss by the interruptions of temporary ceasing run and increasing the level of the run and maintenance. Thus, it is proposed the condition evaluation method of the power equipment, which is based on the defect, testing, operation and so on information. And equipment status evaluation rules, basic data, the evaluation results are consistent data information extraction, identification rule, the equipment specification for intelligent evaluation model are researched and established. In this paper, the proposed method is not only to evaluate the state of power equipment, accurately obtain equipment running status, and improve the efficiency of evaluation, real-time control equipment running status. At the same time, it can effectively support scientific shipment inspection strategy formulation and overall health status of the equipment of multi-dimensional assessment.
\end{abstract}

\section{Introduction}

Power grid equipment are an important for power grid company assets, with the continuous construction and development of power grid, a large number of new equipment put into operation, constantly advanced technology, reliable operation for a growing proportion of new equipment. So, ensuring the safe operation of power equipment, which is more and more important ${ }^{[1-3]}$. And it is more and more high for the user in the requirement of power supply reliability, and because of equipment failure or maintenance outage loss caused by the sometimes serious. In improving the reliability of the equipment operation, therefore, at the same time, also want to ensure that high power will, it puts forward higher requirements on power grid equipment maintenance. State overhaul is an enterprise on the basis of safety, environment and benefit, through to the power grid power transmission and transformation equipment running status evaluation to determine the decisions and carry out equipment maintenance repair work, to achieve safe and reliable equipment operation and maintenance cost of reasonable the equipment maintenance strategy. The state overhaul of the basic flow mainly includes the equipment information collection, equipment condition evaluation and maintenance strategy, maintenance plan, implement several links such as maintenance.

For a long time, our country electric power system of equipment maintenance has been followed "good due to compulsory, compulsory" theory of periodic maintenance. With the rapid development of power grid scale, power equipment, due to the increasing number of distribution is wider, maintenance workload and cost is more and more big, the negative effect of periodic maintenance also reflected. Mainly is (1) under specific standard, big blindness, lack of pertinence. (2) low controllability and control counter measures.(3) state evaluation is not timely, artificial intervention. (4) single assessment mechanism. (5) lacking of maintenance, great resource waste 
and other negative effects ${ }^{[4-6]}$. Aiming at the problems above generally, in this paper, it is proposed the condition evaluation method of the power equipment, which is based on the defect, testing, operation and so on information. And equipment status evaluation rules, basic data, the evaluation results are consistent data information extraction, identification rule, the equipment specification for intelligent evaluation model are researched and established. In this paper, the proposed method is not only to evaluate the state of power equipment, accurately obtain equipment running status, and improve the efficiency of evaluation, real-time control equipment running status. At the same time, it can effectively support scientific shipment inspection strategy formulation and overall health status of the equipment of multi-dimensional assessment.

\section{The Intelligent Condition Evaluation Method for the Power Transmission Equipment}

In this paper, it is proposed the power transmission and transformation equipment condition evaluation method based on fault tree state evaluation, and according to this method development power transmission and transformation equipment state overhaul auxiliary decision support system. The evaluation method according to the amount of equipment state degree of impact on the health status of the equipment, since the childhood is divided into 1, 2, 3, 4 four weight level, corresponding to different weight coefficient. According to the state of degradation is serious, from light to heavy into I, II, III and IV level 4, evaluations of the different values ${ }^{[7-9]}$.Through comprehensive analysis of the state, comprehensive evaluation of equipment state (normal, attention, abnormalities and severe, four state), normal state can run normally, attention state should strengthen the operation monitoring, abnormal state should be arranged timely maintenance, severe state should arrange inspection as soon as possible. Device status measure right attaches great importance to the state of the influence degree of the safe operation of equipment, from light to heavy is divided into four levels, the weight of corresponding weights respectively weight 1 , weight 2 , weight 3 , weight 4 , its coefficient is $1,2,3$, 4.Weight 1,2 and general state of corresponding weights, weight 3 and 4 are corresponding with the important status. State the amount of degradation is depending on the state of degradation from light to heavy is divided into four classes, respectively I, II, III and IV level. Its corresponding basic score is 2, 4, 8, 10 points. Button state quantity score is determined by the state the amount of degradation and weight, the quantity of state should deduct your score is equal to the quantity of state firm points value multiplied by weight coefficient, which is seen in the Table 1 . Not to evaluate a certain quantity of state, no penalty. The following transformer is used for the example. Evaluation of transformer components should be taken into account at the same time points and parts of single state variable total points, unit status evaluation standard are shown in Table 1. When any state points and components combined single points of normal state stipulated in Table 1 at the same time, as a normal state. When any individual points or parts all state amount total points at the same time the attention of the state stipulated in Table 1, as a note. When any amount of individual points of abnormal or severe state stipulated in Table 1, it is the abnormal or severe state.

When all the parts as is normal state, the overall evaluation is normal state. When any parts status to pay attention to the state, abnormal status, or serve state, the overall evaluation should the one of the most serious condition. The overall evaluation of overall is divided into parts total points. 
Table 1. Corresponding to transformer unit status and evaluation points

\begin{tabular}{|c|c|c|c|c|c|c|}
\hline \multirow{2}{*}{$\begin{array}{c}\text { Condition } \\
\text { Parts }\end{array}$} & \multicolumn{2}{|c|}{ Normal State } & \multicolumn{2}{c|}{ Attention State } & Abnormal State & Serve State \\
\cline { 2 - 7 } & Total & Single & Total & Single & Single & Single \\
\hline General & $\leq 30$ & $<10$ & $>30$ & $12 \sim 20$ & 24 & $\geq 30$ \\
\hline Ontology & $\leq 30$ & $<10$ & $>30$ & $12 \sim 20$ & 24 & $\geq 30$ \\
\hline Casing & $\leq 30$ & $<10$ & $\geq 30$ & $12 \sim 16$ & 24 & $\geq 30$ \\
\hline $\begin{array}{c}\text { Non-electricity } \\
\text { protection } \\
\text { system }\end{array}$ & $<30$ & $<10$ & $\geq 30$ & $12 \sim 16$ & 24 & $\geq$ \\
\hline
\end{tabular}

\section{The Typical Default Tree Model of the Transformer}

In this paper, it is proposed method of the intelligent condition evaluation for the power transmission equipment. The very important part is the typical default tree of the power equipment. The typical default tree of the transformer has the general fault, ontology default, casing pipe default and non-electricity protection system default. Each kind of fault has subdivided the maintainable components of equipment.

\section{The Application Results for the Intelligent Evaluation Method}

Transformer based on overall evaluation grading components evaluation grading evaluation is the most serious of the state, the sum of the total points overall is divided into parts. According to the evaluation results of transformer, formulate different maintenance strategies. Normal state can run normally, pay attention to the state still can continue to run, but should strengthen the monitoring in operation, and abnormal state should be arranged timely maintenance, severe state should arrange inspection as soon as possible. This paper puts forward the method to evaluate a certain power supply bureau subordinate equipment, the evaluation results are shown in Table 2.

Table 2. The transformer evaluation results

\begin{tabular}{|c|c|c|c|c|c|c|c|}
\hline \multirow{2}{*}{\multicolumn{2}{|c|}{ Transformer substation }} & \multicolumn{5}{|c|}{ Voltage Level $(\mathrm{kV})$} & \multirow{2}{*}{$\begin{array}{c}\text { Points reasons and } \\
\text { Suggestions }\end{array}$} \\
\hline & & 500 & 220 & 110 & 35 & 10 & \\
\hline \multirow[b]{2}{*}{$\begin{array}{c}110 \mathrm{kV} \\
\text { fuyuan } \\
\text { substation }\end{array}$} & $\begin{array}{l}\text { Equipment } \\
\text { number }\end{array}$ & & & $\begin{array}{l}\text { \#1 and \#2 } \\
\text { transformer }\end{array}$ & & & \multirow{2}{*}{$\begin{array}{c}\text { Run for more than } \\
10 \text { years. Main } \\
\text { transformer } 2,7,8 \\
\# 1 \text { set of cooling } \\
\text { fan can't start. To } \\
\text { strengthen the } \\
\text { operation } \\
\text { monitoring and } \\
\text { arrange } \\
\text { replacement of }\end{array}$} \\
\hline & Group & & & 2 & & & \\
\hline
\end{tabular}




\begin{tabular}{|c|c|c|c|c|c|c|c|}
\hline \multirow{2}{*}{\multicolumn{2}{|c|}{ Transformer substation }} & \multicolumn{5}{|c|}{ Voltage Level $(\mathrm{kV})$} & \multirow{2}{*}{$\begin{array}{l}\text { Points reasons and } \\
\text { Suggestions } \\
\text { motor as soon as } \\
\text { possible }\end{array}$} \\
\hline & & 500 & 220 & 110 & 35 & 10 & \\
\hline \multirow[b]{2}{*}{$\begin{array}{c}110 \mathrm{kV} \\
\text { huize } \\
\text { substation }\end{array}$} & $\begin{array}{l}\text { Equipment } \\
\text { number }\end{array}$ & & & $\begin{array}{c}\text { \#2 } \\
\text { transformer }\end{array}$ & $\begin{array}{c}\# 1 \\
\text { transformer }\end{array}$ & $\begin{array}{c}\# 1 \\
\text { transformer }\end{array}$ & \multirow{2}{*}{$\begin{array}{l}\# 2 \text { main } \\
\text { transformer: seal } \\
\text { aging serious, box } \\
\text { margin slightly oil } \\
\text { leakage, oil } \\
\text { conservator of } \\
\text { ontology oil level } \\
\text { is too low, } \\
\text { operation more } \\
\text { than } 10 \text { years. To } \\
\text { strengthen the } \\
\text { operation } \\
\text { monitoring. } \\
\text { Distribution } \\
\text { change \# } 1 \text { and \# } 1 \\
\text { stand in turn run } \\
\text { more than } 10 \\
\text { years. To } \\
\text { strengthen the } \\
\text { operation } \\
\text { monitoring }\end{array}$} \\
\hline & Group & & & 1 & 1 & 1 & \\
\hline \multirow[b]{2}{*}{$\begin{array}{c}35 \mathrm{kV} \\
\text { Dongshan } \\
\text { substation }\end{array}$} & $\begin{array}{l}\text { Equipment } \\
\text { number }\end{array}$ & & & & $\begin{array}{l}\# 1 \text { and } \# 2 \\
\text { transformer }\end{array}$ & & \multirow{2}{*}{$\begin{array}{l}\text { Run for more than } \\
\text { a decade, \# } 2 \text { main } \\
\text { transformer fan } \\
\text { motor damage } 7 \text {. } \\
\text { To strengthen the } \\
\text { operation } \\
\text { monitoring and } \\
\text { replace the fan } \\
\text { motor as soon as } \\
\text { possible }\end{array}$} \\
\hline & Group & & & & 2 & & \\
\hline \multicolumn{2}{|c|}{ Total } & 0 & 0 & 3 & 3 & 1 & \\
\hline \multicolumn{2}{|c|}{ Total } & \multicolumn{6}{|c|}{66} \\
\hline
\end{tabular}

\section{Conclusions}

Power grid and equipment state overhaul should be fully under the premise of safety running and reliable power supply, on the basis of system construction, to enhance the level of security as the goal, equipment status evaluation as the core, by means of strengthening basic management, standardize equipment management process, to carry out the security responsibility, strengthen the equipment operation state monitoring and analysis, to improve the pertinence and effectiveness of equipment maintenance and maintenance, so as to improve the health level of equipment and power supply reliability. In this paper, it is proposed the condition evaluation method of the power 
equipment, which is based on the defect, testing, operation and so on information. And equipment status evaluation rules, basic data, the evaluation results are consistent data information extraction, identification rule, the equipment specification for intelligent evaluation model are researched and established. In this paper, the proposed method is not only to evaluate the state of power equipment, accurately obtain equipment running status, and improve the efficiency of evaluation, real-time control equipment running status. At the same time, it can effectively support scientific shipment inspection strategy formulation and overall health status of the equipment of multi-dimensional assessment.

\section{References}

[1] "Guide to the interpretation of dissolved and free gasses analysis," IEC Std. 60599, IEC Publication 60599, March 1999.

[2] Barry Finlay, "Oil-filled electrical plant condition assessment interpretation of dissolved gas analysis," Internet Report, Advanced Technology Center, Pacific Power International, Newcastle, Australia, 1995.

[3] R. R. Rogers, "IEE and IEC codes to interpret incipient faults in transformers using gas in oil analysis,” IEEE Trans. Electr. Insul., vol. EI-13, no. 5, pp. 348-354, October 1978.

[4] E. Dorrenburg and W. Strittmatter, "Monitoring oil cooled transformers by gas analysis," Brown Boveil Review, vol. 61, no. 5, pp. 238, 1970.

[5] M. Duval, "Dissolved gas analysis: It can save your transformer," IEEE Elect. Insul. Mag., vol. 5, no. 6, pp. 22-27, 1989.

[6] S. Poyhonen, M. Negrea, A. Arkkio, et al, "Fault diagnostics of an electrical machine with multiple support vector classifiers," IEEE International Symposium on Intelligence Control, 2002.

[7] V. N. Vapnik, "The nature of statistical learn theory," Springer-Verlag, 1995.

[8] Jun Guan, Lizhong Xu, Aiye Shi, "Assessment method of water quality of monitoring data based on support vector machine," Application Research of Computers, vol. 23, no. 9, pp. 36-38, 2006. In Chinese

[9] Zhousuo Zhang, Lingjun Li, Zhengjia He, "Research on diagnosis method of machinery fault based on support vector machine," Journal of Xi' an Jiao Tong Univerisity, vol. 36, no. 12, pp. 1303-1306, 2002.In Chinese 
